\title{
ITR EXTRAFISCAL E A APLICAÇÃO DO DIREITO TRIBUTÁRIO COMO INSTRUMENTO DE DESENVOLVIMENTO SUSTENTÁVEL
}

EXTRA-FISCAL ITR AND THE APPLICATION OF TAX LAW AS A SUSTAINABLE DEVELOPMENT INSTRUMENT

João Pedro Cucolicchio Rosa ${ }^{1}$

ISSUE DOI: $10.21207 / 1983.4225 .360$

\section{RESUMO}

O presente trabalho se propõe a abordar a aplicação do Direito Tributário como artifício de proteção ao meio ambiente natural compreendido como um direito social, transindividual e intergeracional, principalmente no que se desdobra em desenvolvimento sustentável, visitando institutos jurídicos de ambas as áreas. Ademais, o presente vale-se da conceituação de institutos jurídicos, da análise conjunta de outros meios de relação, muito embora aparentem ser bastante discrepantes quando da análise em apartado. Por fim, o desenvolvimento da extrafiscalidade, dos incentivos fiscais e do Imposto Territorial Rural como meios hábeis ao equilíbrio ambiental e a consecução da importante e difícil tarefa de sua proteção.

Palavras-chave: Direito Ambiental. Direito Tributário. Meio Ambiente. Desenvolvimento Sustentável. Equilíbrio Ambiental.

1 Graduado pela Faculdade de Direito de Franca em 2014, pós-graduando em Direito Tributário Pelo Instituto Brasileiro de Estudos Tributários - IBET, advogado. 


\section{ABSTRACT}

This study aims to address the application of the tax law as a protection device to the natural environment understood as a social right, transindividual and intergenerational, especially when it unfolds in sustainable development, visiting legal institutes of both areas. Moreover, this is the valley of the concept of legal institutions, the joint analysis of other connection means, although appear to be a very different when the analysis apart. Finally, the development of extrafiscality, tax incentives and Rural Land Tax as skillful means to the environmental balance and the achievement of important and difficult task of their protection.

Keywords: Environmental Law. Tax Law. Environment. Sustainable Development. Environmental Balance.

\section{INTRODUÇÃO}

É fato notório que com o decorrer dos tempos, os Homens tornam cada vez mais complexas suas interações, não apenas com outros seres da mesma espécie, mas também com os fatores externos que os cercam de forma indissociável.

Como componentes deste ambiente externo pode-se citar a realidade jurídica que visa regulamentar essas complexas relações, a realidade social, cultural, financeira e, principalmente, o meio ambiente.

Desta forma, tais fatores convivem de forma simbiótica com o ser humano, posto que, da fonte que emanam os efeitos das relações intersubjetivas, acabam por emanar resíduos, positivos ou negativos, no ambiente externo, por exemplo: com o decorrer dos anos e com a evolução diária da tecnologia é preciso que surjam regras que a condicionem, é preciso que haja programas sociais que insiram nas camadas mais distantes a tentativa de se equiparar a evolução tecnológica com a realidade social.

E quando se está diante do meio ambiente não é diferente. Ainda no exemplo retro mencionado, com o amadurecimento dos meios comunicacionais, acabam por surgir danos concretos ou, ao menos, perigo que estes ocorram.

Sabe-se, também, e os livros de história, geografia, biologia e ecologia se encarregam de esclarecer, que por muito tempo a sanha de 
acumular patrimônio e renda acabou por tornar o ser humano indiferente quando ao desgaste ambiental, causando ofensas muitas vezes irrecuperáveis, oriundas, justamente, desse crescimento desenfreado e irresponsável, não apenas ao local devastado e proximidades, mas a toda a sociedade, de forma indivisível.

Diante disto, da limitabilidade dos fatores ambientais e da ilimitada gana do ser humano, é forçoso que sejam criados mecanismos de controle para que se torne possível a convivência entre o desenvolvimento econômico e financeiro, mas sem que se distancie do equilíbrio ambiental, em poucas palavras: para que se viabilize o desenvolvimento sustentável.

Para tanto, uma das formas encontradas, que será desenvolvida no presente trabalho, é a possibilidade de utilização do Direito Tributário nessa fórmula, e, consequentemente, aumentar as dimensões do desenvolvimento sustentável.

\section{ASPECTOS GERAIS DO DIREITO AMBIENTAL E A PROTEÇÃO LEGAL DO MEIO AMBIENTE}

Apenas na década de 80 surge a proteção ambiental legal, primeiramente com a lei 6.938 de 1981, denominada Lei da Política Nacional do Meio Ambiente.

Posteriormente, com a constituinte de 1988 é que a proteção ambiental legal é elevada ao patamar de direito constitucionalmente previsto, sem nenhuma menção nas Constituições que a antecederam, inclusive com a criação de um capítulo dedicado ao tema.

É determinação do artigo 225, caput da Constituição.

Art. 225. Todos têm direito ao meio ambiente ecologicamente equilibrado, bem de uso comum do povo e essencial à sadia qualidade de vida, impondose ao Poder Público e à coletividade o dever de defendê-lo e preservá- lo para as presentes e futuras gerações.

A mesma norma constitucional traz em seus parágrafos e incisos uma série de outros instrumentos legais na tentativa de se regulamen- 
tar a proteção ao meio ambiente, mediante atos públicos, como o licenciamento ambiental, estudos ambientais, espaços territoriais especialmente protegidos, acrescidos de imposições legais ao particular, como a previsão do usuário e poluidor pagador.

Outro conceito de fundamental importância para a compreensão do presente trabalho é o de desenvolvimento sustentável.

Em poucas palavras, desenvolvimento sustentável seria a união do desenvolvimento econômico, do avanço da exploração do capital, dos lucros, sem que se deixe de lado o equilíbrio ecológico.

Evidentemente que o desenvolvimento econômico-financeiro está intrinsecamente ligado à exploração ambiental desde os primórdios do surgimento da noção de lucro, capital na mente do ser humano, principalmente pelo fato de os recursos naturais serem as principais matériasprimas exploradas pelo homem.

Tamanha a necessidade de se tornarem harmônicos os interesses ora retratados, a Constituição Federal em seu artigo 170, VI, assim determina:

Art. 170. A ordem econômica, fundada na valorização do trabalho humano e na livre iniciativa, tem por fim assegurar a todos existência digna, conforme os ditames da justiça social, observados os seguintes princípios:

VI - defesa do meio ambiente, inclusive mediante tratamento diferenciado conforme o impacto ambiental dos produtos e serviços e de seus processos de elaboração e prestação;

A preocupação é diretamente proporcional ao socorro que o Mundo pede, diante da exploração desenfreada, da extração de recursos, da extinção de espécies animais e vegetais, da degradação do ar, das águas, do solo, dentre tantas outras ingerências do homem sobre o meio ambiente.

$\mathrm{Na}$ medida em que esses recursos são escassos, enquanto as necessidades humanas são ilimitadas, ganha importância o problema do desequilíbrio ambiental, que acaba por comprometer o desenvolvimento econômico e o meio ambiente. Ainda dentro da esfera de proteção ambi- 
ental, interessante destacar alguns princípios, previstos não apenas na Constituição Federal, mas em outras normas ambientais. ${ }^{2}$

Pode-se compreender, portanto, que o desenvolvimento sustentável não constitui uma regra ambiental genuína, mas sim um ideal que deve ser imputado a toda a sociedade irrestritamente, como norma de conduta ética, permeando todos os atos praticados.

Não há outra saída, portanto, do que a busca de instrumentos de proteção ao desenvolvimento sustentável, traduzindo o equilíbrio, o ponto de balanço entre a exploração econômica e dos recursos ambientais.

Conforme já mencionado, o princípio do poluidor pagador prevê a "exigência do poluidor, uma vez identificado, suportar as despesas de prevenção, reparação e repressão dos danos ambientais". 3

De outra forma, deverá o responsável pelos danos ambientais, arcar com sua restauração in natura, não sendo essa possível, com a indenização pelos prejuízos causados.

Nesse sentido, o Superior Tribunal de Justiça já proferiu em sede do Recurso Especial 769.753 de 08.09.2009, o seguinte entendimento:

11. Pacífica a jurisprudência do STJ de que, nos termos do art.14, $\S 1^{\circ}$, da Lei 6.938/1981, o degradador, em decorrência do princípio do poluidor-pagador, previsto no art. $4^{\circ}$, VII (primeira parte), do mesmo estatuto, é obrigado, independentemente da existência de culpa, a reparar - por óbvio que às suas expensas - todos os danos que cause ao meio ambiente e a terceiros afetados por sua atividade, sendo prescindível perquirir acerca do elemento subjetivo, o que, consequentemente, torna irrelevante eventual boa ou má-fé para fins de acertamento da natureza,

${ }^{2}$ GERENT, Juliana. A Internalização das Externalidades Negativas Ambientais - Uma Breve Análise da Relação Jurídico-econômica. Revista de direito ambiental, São Paulo, n. 44, out.-dez. 2006. p. 41.

3 THOMÉ, Romeu. Manual de Direito Ambiental. $5^{\text {a }}$ Ed. Salvador: Editora jusPODIVM. 2015. P 73. 
conteúdo e extensão dos deveres de restauração do status quo ante ecológico e de indenização. ${ }^{4}$

$\mathrm{Na}$ mesma linha conceitual, surge o princípio do Usuáriopagador, que difere do acima mencionado apenas no sujeito passivo da obrigação. No poluidor pagador, terá o dever de indenizar aquele que causar danos ao meio ambiente a grosso modo; já no usuário pagador, o simples fato do uso de fatores ambientais já dá ensejo ao dever de contraprestação, como forma de manutenção e preservação do ambiente.

Busca-se, diante deste baluarte, "a definição de um valor econômico ao bem natural com o intuito de racionalizar o seu uso e evitar o desperdício" 5 , no fundamento de se compensar financeiramente a coletividade pelo uso de um bem comum do povo.

A contrário senso, o direito ambiental não só vem punir o poluidor ou cobrar do usuário, mas também propõe benefícios àqueles que protegerem o meio ambiente.

Neste diapasão, surge o princípio do protetor recebedor, assim definido por Frederico Amado:

Outro importante princípio ambiental é o do Protetor-Receptor ou Recebedor, que seria a outra face da moeda do Princípio do Poluidor-Pagador, ao defender que as pessoas físicas ou jurídicas responsáveis pela preservação ambiental devem ser agraciadas como benefícios de alguma natureza, pois estão colaborando com toda a coletividade para a consecução do direito fundamental ao meio ambiente ecologicamente equilibrado. ${ }^{6}$

Para finalizar esse primeiro capítulo introdutório a conceitos e institutos de direito ambiental, com o escopo de se demonstrar a preocupação do constituinte com a proteção do meio ambiente, informam os

\footnotetext{
${ }^{4}$ BRASIL, Superior Tribunal de Justiça. Recurso Especial $\mathbf{n}^{\circ}$ 769.753. Disponível em: 〈https://www.digesto.com.br/\#acordaoExpandir/45918>.

${ }^{5}$ THOMÉ, Romeu. Manual de Direito Ambiental. $5^{\text {a }}$ Ed. Salvador: Editora jusPODIVM. 2015. p. 77.

${ }^{6}$ Amado, Frederico Augusto Di Trindade. Direito ambiental esquematizado 5. a ed. - Rio de Janeiro: Forense; São Paulo: Método, 2014. p. 59.
} 
artigos 23, VI e VII, que será de competência comum da União, Estados, Distrito Federal e Municípios a proteção ao meio ambiente, o combate à poluição e a preservação das florestas, da fauna e da flora, ou seja, ampliou-se o âmbito de proteção aos recursos ambientais, conferindo-o a todos os entes federativos.

\section{$2 \quad$ POLÍTICAS PÚBLICAS AMBIENTAIS}

Há que se deixar claro que as imposições legais trazidas a lume, não apenas pelo constituinte, mas também por todos os legisladores infraconstitucionais, não podem ser fórmulas vazias e inócuas. Para tanto, ressaltam-se alguns instrumentos que deverão ser utilizados para o fím colimado acima demonstrado.

A lei 6.938/1981, que dispõe sobre a Política Nacional do Meio Ambiente, mais precisamente em seu artigo $9^{\circ}$, possui um rol de instrumentos dos quais o Poder Público poderá se valer para efetivar os objetivos de busca do desenvolvimento sustentável.

Dentre os instrumentos delineados no dispositivo retro, destaque ao licenciamento ambiental, ao estudo de impacto ambiental e seu respectivo relatório (EIA/RIMA), criação de Espaços Territoriais Especialmente Protegidos (ETEP) e zoneamento ambiental.

Entretanto, o artigo não pode ser interpretado como numerus clausus, sob pena de tornar inócua a busca pelo desenvolvimento sustentável, principalmente pelo dinamismo do direito.

Sendo assim, pode-se considerar também como instrumentos de Política ambiental todo e qualquer exigência legal que busque a efetivação de proteção ambiental em detrimento do desenvolvimento econômico, não apenas na lei da Política Nacional de Meio Ambiente, mas outras tantas pulverizadas pelo ordenamento jurídico, o Cadastro Ambiental Rural - CAR, relatado no novo Código Florestal.

Traçando um elo entre os instrumentos de política ambiental e o presente artigo, surgem os chamados tributos ambientais. Sobre o tema, ensina o professor Frederico Amado:

O Estado deve se valer de todos os meios lícitos para implantar um desenvolvimento econômico sustentável. No Brasil e em inúmeras outras nações, 
cada vez mais o poder de tributar vem sendo utilizado como meio de proteção ao meio ambiente (natural, cultural, artificial ou do trabalho), mediante a instituição dos tributos "verdes", fenômeno que vem sendo intitulado de tributação ambiental, que deve ser enquadrado como mais um instrumento econômico para a realização da Política Nacional do Meio Ambiente. ${ }^{7}$

Importante destacar que, por vezes, a conscientização não é o bastante para criar no Homem o entendimento do que pode ou não fazer, é preciso que se afete seu poderio econômico. A saída para tanto, foi a intervenção estatal por meio do tributo, tanto mediante facilitações trazidas por isenções ou reduções, quanto por agravamentos.

os direitos econômicos são de fundamental
importância para a efetiva aplicação de políticas
ambientais eficazes. Constituem peça essencial no
mecanismo de redução da degradação ambiental,
pois exercem uma forte e constante pressão no
orçamento dos poluidores, compelindo-os a
reconsiderar a possibilidade de adoção de um
comportamento menos nefasto ao meio ambiente. ${ }^{8}$

Já na órbita tributária da questão, os tributos podem atuar de duas formas: direta ou indiretamente.

Atuará de forma direta quando imediatamente estimular condutas favoráveis ao meio ambiente, como a redução de alíquotas, base de cálculo, oferta de isenções ou inibindo condutas lesivas (majoração de tributos no caso de violação das condutas pró-ambiente).

De forma indireta, funcionará quando mediante o direcionamento do produto de arrecadação tributária a programas de incentivo e proteção ambiental, a exemplo da contribuição especial de intervenção econô-

\footnotetext{
${ }^{7}$ Amado, Frederico Augusto Di Trindade. Direito ambiental esquematizado 5. a ed. - Rio de Janeiro: Forense; São Paulo: método, 2014. p. 321.

${ }^{8}$ THOMÉ, Romeu. Manual de Direito Ambiental. $5^{\text {a }}$ Ed. Salvador: Editora jusPODIVM. 2015. p. 832.
} 
mica que incide sobre importação e comercialização de petróleo e seus derivados, popularmente conhecida como CIDE-Combustíveis.

Impende destacar ainda, a questão dos tributos revestidos de extra fiscalidade.

O tributo possui, a grosso modo, duas funções. A arrecadatória que pode ser considerada sua função mais evidente, que se traduz no poder da exação estatal traduzir em "renda" aos cofres públicos. Entretanto, em um segundo plano, o tributo pode assumir um caráter extra fiscal, qual seja o de regular a economia.

De acordo com Paulo de Barros Carvalho:

A compostura da legislação de um tributo vem pontilhada de inequívocas providências no sentido de prestigiar certas situações tidas como social, política ou economicamente valiosas, às quais o legislador dispensa tratamento mais confortável ou menos gravoso. A essa forma de manejar elementos jurídicos usados na configuração dos tributos, perseguindo objetivos alheios aos meramente arrecadatórios, dá-se o nome de extra fiscalidade. ${ }^{9}$

Para Frederico Amado:

Por seu turno, a função extra fiscal ou regulatória dos tributos se faz presente quando o Poder Público torna a arrecadação um instrumento de fomento ou inibição de condutas das pessoas físicas ou jurídicas para o atendimento de algum interesse público. ${ }^{10}$

Sob a roupagem de extra fiscalidade, revestem-se diversos tributos previstos no ordenamento jurídico brasileiro; destaque neste ponto, ao ITR - Imposto Territorial Rural, ICMS, CIDE-combustível, Impostos alfandegários.

${ }^{9}$ CARVAlHO, Paulo de Barros. Curso de Direito Tributário/Paulo de Barros Carvalho. - 24. Ed. - São Paulo: Saraiva, 2012. p. 142.

${ }^{10}$ Amado, Frederico Augusto Di Trindade. Direito ambiental esquematizado -

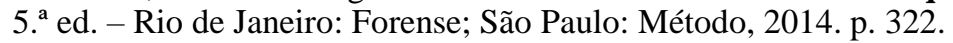




\section{O ITR, SUA FUNCCÃO EXTRAFISCAL E SUA IMPORTÂNCIA NA BUSCA DE UM DESENVOLVIMENTO SUSTENTÁVEL}

O imposto territorial rural está previsto na Constituição Federal no artigo 153, VI e §4 $4^{\circ}$ além da sua lei criadora 9.393/1996.

Art. 153. Compete à União instituir impostos sobre:

VI - propriedade territorial rural;

$\S 4^{\circ} \mathrm{O}$ imposto previsto no inciso VI do caput:

I - será progressivo e terá suas alíquotas fixadas de forma a desestimular a manutenção de propriedades improdutivas;

II - não incidirá sobre pequenas glebas rurais, definidas em lei, quando as explore o proprietário que não possua outro imóvel;

III - será fiscalizado e cobrado pelos Municípios que assim optarem, na forma da lei, desde que não implique redução do imposto ou qualquer outra forma de renúncia fiscal.

O ITR é, portanto, um imposto que possui a seguinte regra matriz de incidência tributária:

Antecedente:

Critério material (fato gerador): a propriedade, domínio útil ou a posse de imóvel por natureza, como definido na lei civil, localizado fora da zona urbana do Município.

Critério Temporal: $1^{\circ}$ de janeiro de cada ano.

Critério Espacial: Território nacional, pois se trata de imposto de competência da União.

Consequente:

Critério Pessoal:

Ativo: União.

Passivo: Proprietário, possuidor ou titular do domínio útil do imóvel.

Critério Quantitativo:

Base de cálculo: Valor da Terra Nua - VTN.

Alíquota: Variável entre $0,03 \%$ até $20 \%$. 
A respeito do imposto acima esquematizado, o que chama a atenção para a compreensão do presente artigo consiste inicialmente na alíquota do ITR, que, por sua vez, é estabelecida na tabela de alíquotas anexa à Lei 9.393/96, variando conforme o tamanho do imóvel, em hectares, e o grau de utilização - GU. O grau de utilização é obtido pela relação percentual entre a área efetivamente utilizada e a área aproveitável. ${ }^{11}$

Note-se o evidente caráter regulador do ITR quando busca, por meio de suas alíquotas variáveis, evitar latifúndios e propriedades improdutivas, ao tornar a percentagem arrecadatória maior, quanto menor o grau de produtividade da terra, tornando plenamente eficaz a regra do artigo 153, $\S 4^{\circ}$, I da Carta da República já demonstrada anteriormente.

Neste diapasão, é cristalino que o ITR possui um perfil extrafiscal bastante acentuado, na busca de se obstar que os grandes proprietários rurais abusem de seu direito de propriedade, sem pensar na função social que essa pode desempenhar, ou seja, atua como um instrumento auxiliar do disciplinamento estatal da propriedade rural $^{12}$.

Importante destacar, que, caso a propriedade rural não receba o adequado tratamento a fim de se tornar plenamente produtiva, poderá sofrer o proprietário, sérias sanções, inclusive a desapropriação para fins de reforma agrária, conforme lei 8.629/93.

D'outro modo, o legislador infraconstitucional buscou a efetivação da política de proteção ambiental quando concedeu certos benefícios fiscais às propriedades rurais que possuíssem áreas de interesse ambiental.

A extrafiscalidade ambiental do ITR também é constatada quando o legislador infraconstitucional excluiu da área tributável as de preservação permanente e de reserva legal; de interesse ecológico para a proteção dos ecossistemas, assim declaradas mediante ato do órgão competente; sob regime de servidão florestal ou ambiental e as cobertas por

${ }^{11}$ MELO, José Eduardo Soares de; PAULSEN, Leandro. Impostos federais, estaduais e municipais. 7. ed. rev. e atual. -Porto Alegre: Livraria do Advogado Editora, 2012. p. 225.

${ }^{12}$ MACHADO, Hugo de Brito. Curso de Direito Tributário. 26ª ed. São Paulo: Malheiros, 2005. p. 343. 
florestas nativas, primárias ou secundárias em estágio médio ou avançado de regeneração. ${ }^{13}$

É a determinação legal do artigo $10, \S 1^{\circ}$, II da lei do ITR:

$\S 1^{\circ}$ Para os efeitos de apuração do ITR, considerarse-á:

II - área tributável, a área total do imóvel, menos as áreas:

a) de preservação permanente e de reserva legal, previstas na Lei $\mathrm{n}^{\circ} 12.651$, de 25 de maio de 2012;

b) de interesse ecológico para a proteção dos ecossistemas, assim declaradas mediante ato do órgão competente, federal ou estadual, e que ampliem as restrições de uso previstas na alínea anterior;

c) comprovadamente imprestáveis para qualquer exploração agrícola, pecuária, granjeira, aquíícola ou florestal, declaradas de interesse ecológico mediante ato do órgão competente, federal ou estadual;

d) sob regime de servidão ambiental;

e) cobertas por florestas nativas, primárias ou secundárias em estágio médio ou avançado de regeneração;

f) alagadas para fins de constituição de reservatório de usinas hidrelétricas autorizada pelo poder público.

Trata-se de incentivo econômico para a preservação das áreas ambientalmente protegidas. Utilizando-se do instrumento da extra fiscalidade, o Poder Público, através de isenções fiscais, incentiva comportamentos ambientalmente corretos. O Superior Tribunal de Justiça já se manifestou sobre a não tributação de áreas ambientalmente protegidas:

ITR. ÁREA. PRESERVAÇÁO PERMANENTE. IBAMA.

A Turma reiterou o entendimento de que o imposto territorial rural (ITR) é tributo sujeito a lançamento

${ }^{13}$ AMADO, Frederico Augusto Di Trindade. Direito ambiental esquematizado - 5. ${ }^{\text {a }}$ ed. - Rio de Janeiro: Forense; São Paulo: MÉTODO, 2014. p. 326. 
por homologação e que o art. $10, \S 7^{\circ}$, da Lei n. 9.39311996 permite a exclusão da área de preservação permanente da base de cálculo do referido imposto, sem necessidade de ato declaratório ambiental do IBAMA. Precedentes citados: REsp 812 . 1 04-AL, D]1 0/ 1 2/2007, e REsp 587.429-AL, DJ 2/8/2004. (REsp 898. 537GO, Rei. Min. Eliana Calmon, julgado em 6/ 11 /2008.). ${ }^{14}$

Importante frisar que, caso o proprietário institua em sua propriedade o mínimo previsto em lei de áreas de proteção ambiental, essas serão abatidas do total da área da propriedade, chegando-se, assim, ao valor da terra nua tributável, ou seja, o sujeito passivo do ITR, seja ele o proprietário, possuidor ou titular do domínio útil, ao mesmo tempo em que se sentir individualmente "lesado" diante da necessária destinação de sua terra a interesses coletivos, será beneficiado pela isenção que incidirá na proporção da área de interesse ambiental.

Ademais, caso opte por instituir uma Reserva Legal, acima do quantum estipulado em lei, quais sejam, $80 \%$ em propriedades rurais localizadas na Amazônia Legal; 35\% das propriedades rurais localizadas no cerrado e $20 \%$ das propriedades rurais localizadas nos demais espaços do Brasil, a área excedente também será contemplada com a isenção, ou seja, incentiva o sujeito passivo do ITR a praticar atos de proteção ambiental, na medida em que verá o abatimento proporcional no valor a ser pago perante o fisco.

Caso o proprietário destine à área de Reserva Legal um percentual superior ao exigido pela legislação, a isenção tributária incidirá sobre toda aquela área, tendo em vista a função extra fiscal da norma, cujo intuito é exatamente incentivar comportamentos ambientalmente corretos. Nesse sentido as seguintes decisões do STJ : - REsp 1 . 158.999 / se. Rei. Min. Eliana Calmon. Publ. DJe17 /08/2010. - REsp 1 .

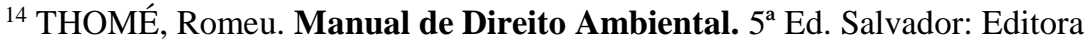
jusPODIVM. 2015. p. 835.
} 
220.746 / SC. Rei. Min. Mauro Campbell Marques. Publ. DJe 04/03/20 $11 .^{15}$

Interessante a verificação de que, nas situações a lume, não se trata de intervenção econômica para o mal do contribuinte, posto que não lhe enseja nenhum tipo de punição por descumprimento, mas sim uma benesse oriunda de um ato que certamente beneficiará o meio ambiente.

Essa forma de atuação, tanto do legislador, quanto da administração pública, contempla o princípio do provedor recebedor, conceituado no início do presente artigo.

Ou seja, quando se fala de tributos ambientais, não se refere apenas a uma errônea noção que se possa ter como punição, mas sim um beneficiamento que o particular pode vir a ter caso opte por atuar de forma incentivadora e protetora ao meio ambiente que o cerca.

Embora possa parecer o mais lógico, a criação de mais um tributo visando outra oneração ao contribuinte, que já é severamente atingido pela carga tributária do sistema brasileiro, o legislador encontrou uma saída bastante saudável para incentivar a atuação pro natura do contribuinte.

Embora pareça a solução mais coerente aos olhos de boa parte da doutrina, a criação de novos tributos (greentax - "imposto verde"), que tenham por hipótese deincidência um ato potencialmente lesivo ao meio ambiente, só faria por agravar, ainda mais, os encargos existentes sobre o contribuinte brasileiro - que, diga-se, é um dos mais onerados do mundo - , sem que isso importe na espera da quebra de paradigma, reformulando a sistemática tributária nacional, há muito desiludida com promessas falaciosas de reforma. ${ }^{16}$

Assim é a aplicação do Imposto Territorial Rural, como corolário da busca de equilíbrio ambiental e desenvolvimento econômico, ofer-

\footnotetext{
15 THOMÉ, Romeu. Manual de Direito Ambiental. $5^{\text {a }}$ Ed. Salvador: Editora jusPODIVM. 2015. p. 836.

${ }_{16}$ TRENNEPOHL, Terence Dornelles. Incentivos fiscais no direito ambiental. São Paulo: Saraiva, 2008. p. 126.
} 
tando ao sujeito passivo do respectivo imposto o direito de se beneficiar quando optar por atuar de forma a beneficiar o meio ambiente.

\section{CONSIDERAÇÕES FINAIS}

Diante de todas as explanações aduzidas no presente artigo, desde as conceituações dos institutos de direito ambiental, seus instrumentos de proteção, princípios, até o direito tributário e suas peculiaridades, busca-se a ligação entre os ramos do Direito de forma que possa tornar viável a tomada de medidas protetivas ao meio ambiente por parte, não só do poder público, mas também dos particulares, como escopo do princípio da participação.

Incide, neste ponto, o direito tributário, mais precisamente o imposto territorial rural, ITR, que em sua concepção, tanto a nível constitucional quanto infraconstitucional, deverá ser observada a forma com que o proprietário, possuidor ou titular do domínio útil do imóvel rural aproveita de sua propriedade.

Se de forma a contemplar a função social da propriedade, bem como do desenvolvimento sustentável, aliando a exploração da terra à utilização desta ao benefício ambiental, o imposto incidirá de forma mais branda, sendo, inclusive, abatido deste, o percentual respectivo a áreas de preservação ambiental, reserva legal, dentre outras, conforme o artigo 10 da lei do ITR aduz.

Buscou-se, também, demonstrar que a forma mais benéfica encontrada pelo legislador foi a de criar benefícios fiscais ao contribuinte, não o onerando mais do que já é, sob pena de, se assim agisse, tornar inviável a exploração econômica de imóvel rural, o que, certamente, geraria um contra efeito nefasto, tanto à economia quanto ao meio ambiente.

\section{REFERÊNCIAS BIBLIOGRÁFICAS}

BRASIL, Superior Tribunal de Justiça. Recurso Especial $\mathbf{n}^{\circ} \mathbf{7 6 9 . 7 5 3 .}$ Disponível em: $<$ https://www.digesto.com.br/\#acordaoExpandir/45918> Acesso em 15 jun. 2016 
CARVAlHO, Paulo de Barros. Curso de Direito Tributário/Paulo de Barros Carvalho. - 24. Ed. - São Paulo: Saraiva, 2012.

DI TRINDADE, Amado, Frederico Augusto. Direito ambiental esquematizado -5 . $^{\text {a }}$ ed. - Rio de Janeiro: Forense; São Paulo: MÉTODO, 2014.

GERENT, Juliana. A Internalização das Externalidades Negativas Ambientais - Uma Breve Análise da Relação Jurídico-econômica. Revista de direito ambiental, São Paulo, n. 44, p. 40-63, out.-dez. 2006.

MACHADO, Hugo de Brito. Curso de Direito Tributário. $26^{a}$ ed. São Paulo: Malheiros, 2005.

MELO, José Eduardo Soares de; PAULSEN, Leandro. Impostos federais, estaduais e municipais. 7. ed. rev. e atual. -Porto Alegre: Livraria do Advogado Editora, 2012

THOMÉ, Romeu. Manual de Direito Ambiental. 5 ${ }^{\text {a }}$ Ed. Salvador: Editora jusPODIVM. 2015.

TRENNEPOHL, Terence Dornelles. Incentivos fiscais no direito ambiental. São Paulo: Saraiva, 2008. 